\title{
Gallbladder Disease in the Aged Patient- A Comprehensive Diagnosis and Treatment Approach
}

\author{
Sharon Ziskind ${ }^{1}$, Uri Netz ${ }^{2}$, Udit Gibor ${ }^{2}$, ShaharAtias ${ }^{2}$, Leonid Lantsberg ${ }^{2}$ and Zvi H Perry ${ }^{1,2 *}$ \\ ${ }^{1}$ Soroka University Medical Center, Israel \\ ${ }^{2}$ Department of Epidemiology and Health Management, Ben-Gurion University of the Negev, Israel
}

Submission: September 01, 2017; Published: November 22, 2017

*Corresponding author: Zvi Perry, MD, MA, Surgical Ward A, Soroka University Medical Center P0 Box 151, Beer-Sheva 64101, Israel, Tel: +972-8-6400610; Fax: +972-8-6477633; Email: zperry@bgu.ac.il

\begin{abstract}
The improvements in life expectancy combined with aging of the baby boomer generation will result in a rapid increase in the population older than 65 years in the next few decades, and thus an increase in the need to take care of elderly patients. The authors of this chapter were born and raised in Israel, a country in which due to the holocaust and the fact it was a young nation, was not accustomed to elderly patients. But, in the last decade the percentage of patients older than 65 has crossed the $10 \%$ mark of the entire population and we were forced to learn and to find ways to care and treat older patients. As the saying in pediatrics, that a child is not a small adult, the same rule applies seemingly to elderly patients and the know how in treating them is not the same as the 30 years old patient. It is important to do so, because It is expected that by 2030 one in five people will be older than 65 years, with the most rapidly growing segment of this older population being persons older than 85. This number is expected to increase fivefold and reach 20 million by 2050.

Gallbladder disease is no stranger to patients of older ages, if at all it even afflicts older patients more. But, older patients suffer from other ailments and physiological derangements which make the diagnosis and treatment of gallbladder diseases harder than in younger patients. The purpose of the current article is the shed some light on the problems and challenges treating and diagnosing gallbladder disease in the elderly, as well as some unique solutions for this age group. We will mainly direct our attention to acute cholecystitis which is very frequent and might be fatal at this age group, which has unique characteristics.
\end{abstract}

Keywords: Gallbladder disease; Elderly patients; Cholecystitis

\section{Introduction}

Biliary diseases are a wide spectrum of medical conditions, that variate between asymptomatic gallbladder stones through symptomatic gallbladder stones (i.e. biliary colic, acute cholecystitis) and symptomatic common bile duct stones as cholangitis. Risk factors associated with gallstones are female gender, increasing age, ethnicity, obesity, metabolic syndrome, rapid weight loss, certain diseases (cirrhosis and crohn's disease), gallbladder stasis (from spinal cord injury or drugs, such as somatostatin) and lifestyle [1]. Of all those possible pathways that involve the biliary tree, one of the most common manifestations is acute cholecystitis. Acute cholecystitis is defined as a prolonged blockage of the cystic duct by biliary stone/s. The obstruction is not reversible, followed by inflammation, stasis of bile and super-infection. The clinical presentation consists of fever, right upper quadrant pain, tenderness to palpation and guarding. Diagnosis is usually based on history and physical examination, laboratory results and trans-abdominal ultrasound. The management of a patient with acute cholecystitis usually consists of antibiotics treatment and a surgical procedure later on, or a surgery within 48-72 hours of the onset of symptoms. In 2016, new guidelines have been published by the World Society of Emergency Surgery that shed light on some grey areas regarding the conservative and invasive management of such patients [2]. There is now greyer area than the management of biliary disease, and especially acute cholecystitis than in the elderly patient. The elderly population ( $>65$ years old) is a unique sub-population that has grown extensively in the recent decades. Regarding this population, additional considerations should be taken into account in accordance to the patient's comorbidities and frailty status while determining the best surgical approach to this patient. 
Frailty can be defined as a lack of physiological reserve, seen across multiple organ systems, and is an independent predictor of mortality and morbidity after surgery [3]. Since there is a wide spectrum of patients $>65$ years old, one cannot treat all of them in the same manner [4]. As an example for solving this challenge, Riall et al. [5] reported about a prognostic model that accurately predicted the 2-year risk of emergent gallstone-related hospitalizations in older patients having symptomatic gallstones. They suggested to use that model in clinical practice in order to improve outcomes in elderly patients with symptomatic gallstones.

The objective of the current literature review is to evaluate the cumulative data concerning the management of an elderly patient with biliary disease, with an emphasis upon acute cholyctitis. Since this topic occupied the surgical community for a long time [6-9], we have decided to focus on publications from the recent 5 years.

A Pubmed search was undertaken for articles in the English language, using the following key words: acute cholecystitis; cholecystectomy; laparoscopic cholecystectomy; cholecystotomy; elderly patients; elderly population; geriatric patients. We decided to show the results of this search in around a few specific areas, like operative management in the elderly, is cholecystectomy feasible in older patients and complications seen in elderly patients with biliary disease. We will start our discussion with the basic question is surgery really applicable for elderly patients?

\section{Is cholecystectomy feasible in the elderly population?}

Several studies deal with the safety issue regarding cholecystectomy in the elderly. Agrusa et al. [10] conducted 416 cholecystectomies in patients $>65$ years old between the years 2010 2014. They found higher rates of primary open cholecystectomy in the elderly group (3.7\% in the younger group vs. $9.2 \%$ in the elderly group), higher conversion rate in the older group $(1.2 \%, \mathrm{p}>0.05)$ and higher rates of laparoscopic cholecystectomy in emergency settings in the elderly group ( $10.3 \%$ vs. $13.8 \%)$. They concluded that laparoscopic cholecystectomy is a feasible, safe procedure in elderly patients [10]. Ambe et al. [11] compared the pre-operative, intra-operative and post-operative characteristics of 74 patients $>70$ years old with 78 patients $<70$ years old. They reported higher rates of severe cholecystitis in the elderly group, as well as higher mean WBC, CRP and APACHE II score. On the other hand, they did not find a significant difference regarding the duration of anesthesia and duration of surgery. The complications rates were higher in the elderly group $(\mathrm{p}=0.01)$. They concluded that the patient's age cannot be the only factor in the decision about surgery [11].

Fewer studies have specifically focused on older patients. Lee et al. assessed the outcome of laparoscopic cholecystectomy in patients $>80$ years old. They found the Lap approach safe and feasible, and suggest to consider it as the gold standard [12]. Additional data arise from Dubecz et al. [13] which reported the outcome of 22 cholecystectomies, conducted in patients $>90$ years old. The authors noted that cholecystitis found to be a neglected condition in this population [13]. In this study, cholecystectomies were found to be safe with acceptable perioperative morbidity and mortality, even as an emergency procedure.

Additional studies have evaluated the relevance of comorbidities upon the decision to operate. Hewitt et al. [14] evaluated data of 413 patients $>65$ years who were admitted in an emergency setting. They found that most of the patients suffered from multi comorbidities (defined as presence of 2 or more medical conditions). They recommend that multi morbidity will not be a barrier for surgical interventions.

In-between results and conclusions are demonstrated by Nielsen et al. In this study, age found to be an independent predictor for worse outcome after cholecystectomy. However, they found elective laparoscopic cholecystectomy, when repeated gallstone symptoms occurred, as an appropriate management for the elderly patients [14].

Different conclusions were reached by McGillicuddy et al. [15] who listed 290 patients $>65$ years, that were diagnosed with acute cholecystitis and underwent lap cholecystectomy. The conversion rate to open cholecystectomy was $20.3 \%$; approximately $20 \%$ suffered from post-operative complications. 185 patients with acute cholecystitis hadn't been operated; in this group, $36 \%$ underwent percutaneous cholecystectomy, while $24 \%$ had elective cholecystectomy. The conclusion of the investigators was that postoperative morbidity was significant in the elderly, and they suggested that medical management with interval cholecystectomy only be considered for recurrent episode of acute cholecystitis, and that this strategy may be appropriate in selected patients [16].

\section{Operative management in the elderly}

Several studies deal with the question of how to conduct the cholecystectomy in the elderly. In our review, we found reference for four different aspects regarding the surgical approaches:

Timing: Haltmeier et al. [17] compared the results of early vs. late cholecystectomy for acute cholecystitis in the elderly patients with comorbidities. They found that early intervention was associated with shorter postoperative stay, and no increase in complications rate [17]. Ferrarese et al. [18] analyzed the outcome of early and delayed 114 cholecystectomies conducted in their institution. They found laparoscopic cholecystectomy a safe and effective treatment for cholelithiasis and acute cholecystitis in ordinary and emergency settings [18].

Open vs laparoscopic cholecystectomy: Kuwabara et al. [19] compared 1742 laparoscopic cholecystectomies with 810 open cholecystectomies conducted in patients $>60$ years old in Japan. Longer LOS, higher total charges and more complications were observed for open cholecystectomies [19].

The surgical approach: Hu et al. [20] reported an evaluation of B mode ultrasound guided percutaneous trans-hepatic gallbladder drainage combined with laparoscopic cholecystectomy for acute cholecystitis in 35 elderly patients, compared with 35 controls that underwent only laparoscopic cholecystectomy. They found the 
combination approach superior to laparoscopic cholecystectomy alone since minimal wounding, accelerated recovery, higher safety and efficacy and fewer complications had been shown in the treatment group [20]. One must admit that this approach needs not only specific equipment but a learning curve that might make it less feasible.

An alternative approach is SILC- Single Incision Laparoscopic Cholecystectomy (SILC), that has been evaluated by Rizzuto et al. [21]. They found SILC as an effective and safe procedure for the elderly population, with significantly lower levels of postoperative pain. They suggest SILC as an alternative to the standard laparoscopic approach on a routine basis.

Conservative approach by percutaneous cholecystostomy: Percutaneous cholecystostomy is an option to manage acute cholecystitis, mainly in high risk patients (i.e. septic patients, or a patient with severe comorbidities). This approach may be the definitive treatment or a temporary one, before definitive surgery. Howard et al. report on their success to manage patients with cholecystostomy alone [22]. Seok Jang et al. [23] compared retrospectively 31 high risk patients who were treated with cholecystostomy alone with 62 patients with cholecystostomy followed by laparoscopic cholecystectomy. They found percutaneous cholecystostomy safe and effective therapeutic option in high risk patients [23]. Another study, conducted by Byung-Gon Na et al. [24] demonstrated percutaneous transhepatic gallbladder drainage as a proper preoperative management before laparoscopic cholecystectomy in the elderly patients with acute cholecystitis [24].

Complications in the elderly population: One of the major challenges regarding the elderly population is the higher prevalence of complications. The incidence of severe sepsis was evaluated by Ukkonen et al. [25] and found that severe sepsis after surgery in the elderly population is rare, but fatal [25]. Another study that evaluated the outcomes of cholecystectomy of elderly in comparison with younger adults, did not find any difference in the major outcomes and in the complications rate; however, the evaluated outcomes did not include important geriatric outcomes, such as delirium [26]. Fukuda et al. [27] evaluated the clinical features of 94 patients $>80$ years who underwent emergency surgery for acute abdominal diseases and determinate the factors predicting mortality in these patients. They found that using the disease scoring system (POSSUM) can predict mortality in those patients, as well as the delay in hospital admission.

\section{Summary}

In this review, we aimed to evaluate the cumulative data regarding the management of acute cholecystitis in the elderly population, with a focus on the surgical approach. Most studies that have been assessed in the current report, have found laparoscopic cholecystectomy feasible, safe and the appropriate management for acute cholecystitis in the elderly population.
Improving the results of the traditional laparoscopic cholecystectomy approach was suggested by different investigators by using SILC or B-mode mode ultrasound guided percutaneous trans-hepatic gallbladder drainage combined with the laparoscopic cholecystectomy. We believe that further evaluation of these approaches should be conducted before updating the current guidelines.

Beyond that, we believe that stratification by age or by fragility status is required while evaluating the elderly population, since it is too heterogenic population. Substantial support for this consideration arises from studies that were evaluated in the current review and focused on specific ages.

\section{References}

1. Stinton LM, Myers RP, Shaffer EA (2010) Epidemiology of Gallstones. Gastroenterol Clin North 39(2): 157-169.

2. Ansaloni L, Pisano M, Coccolini F, Peitzmann AB, Fingerhut A, et al. (2016) 2016 WSES guidelines on acute calculous cholecystitis. World J Emerg Surg 11: 25.

3. Partridge JS, Harari D, Dhesi JK (2012) Frailty in the older surgical patient : a review. Age Ageing 41(2): 142-147.

4. Deiner S, Westlake B, Dutton RP (2014) Patterns of Surgical Care and Complications in the Elderly Stacie. J Am Geriatr Soc 62(5): 829-835.

5. Riall TS, Adhikari D, Parmar AD, Linder SK, Dimou FM, et al. (2015) The Risk Paradox: Use of Elective Cholecystectomy in Older Patients Is Independent of Their Risk of Developing Complications. J Am Coll Surg 220(4): 682-690.

6. Strodel WE, Sirinek KR, Bingener J, Richards ML, Schwesinger WH (2003) Laparoscopic Cholecystectomy for Elderly Patients Gold Standard for Golden Years? Arch Surg 138(5): 531-535.

7. Tambyraja AL, Kumar S, Nixon SJ, Ch B (2004) Outcome of Laparoscopic Cholecystectomy in Patients 80 Years and Older. World J Surg 28(8): 745-748.

8. Hazzan D, Geron N, Golijanin D, Reissman P, Shiloni E (2001) Laparoscopic cholecystectomy in octogenarians. Surg Endosc Other Interv Tech: 773-776.

9. Majeski J (2004) Laparoscopic cholecystectomy in geriatric patients. Am J Surg 187(6): 747-750.

10. Agrusa A, Romano G, Frazzetta G, Chianetta D, Sorce V, et al. (2014) Role and outcomes of laparoscopic cholecystectomy in the elderly. Int J Surg 12(S2): S37-S39.

11. Ambe PC, Weber SA, Christ H, Wassenberg D (2015) Primary cholecystectomy is feasible in elderly patients with acute cholecystitis. Aging Clin Exp Res. Springer International Publishing 27(6): 921-926.

12. Lee S, Na B, Yoo Y, Mun S, Choi N (2015) Clinical outcome for laparoscopic cholecystectomy in extremely elderly patients. Ann Surg Treat Res 88(3): 145-151.

13. Dubecz A, Langer M, Stadlhuber RJ, Schweigert M, Solymosi N, et al. (2012) Cholecystectomy in the Very Elderly-Is 90 the New 70? J Gastrointest Surg 16(2): 282-285.

14. Nielsen LBJ, Harboe KM, Bardram L (2014) Cholecystectomy for the elderly: No hesitation for otherwise healthy patients. Surg Endosc Other Interv Tech 28(1): 171-177.

15. McGillicuddy EA, Schuster KM, Barre K, Suarez L, Hall MR, et al. (2012) Non-operative management of acute cholecystitis in the elderly. Br J Surg 99(9): 1254-1261. 
16. Hewitt J, Mccormack C, Tay HS, Greig M, Law J, et al. (2016) Prevalence of multimorbidity and its association with outcomes in older emergency general surgical patients : an observational study. BMJ Open 6(3): 1-6.

17. Haltmeier T, Benjamin E, Inaba K, Lam L, Demetriades D (2015) Early versus delayed same-admission laparoscopic cholecystectomy for acute cholecystitis in elderly patients with comorbidities. J Trauma Acute Care Surg 78(4): 801-807.

18. Ferrarese AG, Solej M, Enrico S, Falcone A, Catalano S, et al. (2013) Elective and emergency laparoscopic cholecystectomy in the elderly: our experience. BMC Surg 13(2): S21.

19. Kuwabara K, Matsuda S, Fushimi K, Ishikawa KB, Horiguchi H (2011) Relationships of age , cholecystectomy approach and timing with the surgical and functional outcomes of elderly patients with cholecystitis. Int J Surg 9(5): 392-399.

20. Hu Y, Pan J, Tong X, Li K, Chen S, et al. (2015) Efficacy and safety of B-mode ultrasound- guided percutaneous transhepatic gallbladder drainage combined with laparoscopic cholecystectomy for acute cholecystitis in elderly and high-risk patients. BMC Gastroenterol 15 2-7.

21. Rizzuto A, Serra R, Mignogna C, Palaia I, Ulrich F (2016) Single incision laparoscopic cholecystectomy in geriatric patients. Int J Surg 35: 83-87.
22. Howard JM, Hanly AM, Keogan M, Ryan M, Reynolds JV (2009) Percutaneous Cholecystostomy- A Safe Option in the Management of Acute Biliary Sepsis in the Elderly. Int J Surg 7(2): 94-99.

23. Seok W, Jun J, Lim U, Ro K (2015) Outcome of conservative percutaneous cholecystostomy in high-risk patients with acute cholecystitis and risk factors leading to surgery. Surg Endosc 29(8): 2359-2364.

24. Na B, Yoo Y, Mun S, Kim S, Lee H, et al. (2015) The safety and efficacy of percutaneous transhepatic gallbladder drainage in elderly patients with acute cholecystitis before laparoscopic cholecystectomy. Ann Surg Treat Res 89(2): 68-73.

25. Ukkonen M, Karlsson S, Laukkarinen J, Rantanen T (2016) Severe Sepsis in Elderly Patients Undergoing Gastrointestinal Surgery- a Prospective Multicenter Follow-up Study of Finnish Intensive Care Units. J Gastrointest Surg 20(5): 1028-1033.

26. Fuksm D, Duhaut P, Mauvais F, Haccart V, Paquet C, et al. (2015) A Retrospective Comparison of Older and Younger Adults Undergoing Early Laparoscopic Cholecystectomy for Mild to Moderate Calculous Cholecystitis. J Am Geriatr Soc.

27. Fukuda N, Wada J, Niki M, Sugiyama Y, Mushiake H (2012) Factors predicting mortality in emergency abdominal surgery in the elderly. World J Emerg Surg 7(1): 12.

\section{Your next submission with Juniper Publishers will reach you the below assets}

- Quality Editorial service

- Swift Peer Review

- Reprints availability

- E-prints Service

- Manuscript Podcast for convenient understanding

- Global attainment for your research

- Manuscript accessibility in different formats

( Pdf, E-pub, Full Text, Audio)

- Unceasing customer service

Track the below URL for one-step submission https://juniperpublishers.com/online-submission.php 